Review

\title{
Fungal Biology and Agriculture: Revisiting the Field
}

\author{
O. Yarden, ${ }^{1}$ D. J. Ebbole, ${ }^{2}$ S. Freeman, ${ }^{3}$ R. J. Rodriguez, ${ }^{4}$ and M. B. Dickman ${ }^{5}$ \\ ${ }^{1}$ Department of Plant Pathology and Microbiology, Faculty of Agricultural, Food and Environmental Quality Sciences, The \\ Hebrew University of Jerusalem, Rehovot 76100, Israel; ${ }^{2}$ Department of Plant Pathology and Microbiology, Texas A\&M \\ University, College Station 77843-2132, U.S.A.; ${ }^{3}$ Department of Plant Pathology, Agricultural Research Organization, The \\ Volcani Center, P.O. Box 6, Bet Dagan 50250, Israel; " United States Geological Survey, WFRC, 6505 NE 65th Street, \\ Seattle, WA 98115, and Biology Department, University of Washington, Seattle 98195, U.S.A.; ${ }^{5}$ Department of Plant \\ Pathology, University of Nebraska-Lincoln, Lincoln 68583-0722, U.S.A.
}

Submitted 27 January 2003. Accepted 16 June 2003.

Plant pathology has made significant progress over the years, a process that involved overcoming a variety of conceptual and technological hurdles. Descriptive mycology and the advent of chemical plant-disease management have been followed by biochemical and physiological studies of fungi and their hosts. The later establishment of biochemical genetics along with the introduction of DNA-mediated transformation have set the stage for dissection of gene function and advances in our understanding of fungal cell biology and plant-fungus interactions. Currently, with the advent of high-throughput technologies, we have the capacity to acquire vast data sets that have direct relevance to the numerous subdisciplines within fungal biology and pathology. These data provide unique opportunities for basic research and for engineering solutions to important agricultural problems. However, we also are faced with the challenge of data organization and mining to analyze the relationships between fungal and plant genomes and to elucidate the physiological function of pertinent DNA sequences. We present our perspective of fungal biology and agriculture, including administrative and political challenges to plant protection research.

Only a minority of the known fungal species cause plant diseases. However, many fungal species, including pathogens, have nonpathogenic associations with plants that impact plant health. We lack knowledge of the basic mechanisms of these associations and a clear understanding of what factors distinguish pathogenic from other plant-fungus interactions. Fundamental questions remain unanswered, such as what drives the expression and transition between fungal symbiotic lifestyles (e.g., pathogenic, mutualistic, commensal) how do new pathogenic races evolve, and what genetic or biochemical factors control host range. Regardless of phylogenetic origin or ecological adaptation, the accumulated evidence strongly supports a key role for signaling (or external signal perception) in the determination of a given fungal lifestyle and in the outcome of interactions between fungi and other organisms. Fungal genome sequences are revolutionizing the research approaches for addressing these questions. It is now becoming clear that

Corresponding authors: O. Yarden; E-mail: Oded.Yarden@huji.ac.il; Telephone: +972 8 9489298; Fax: +972-8-9468785; and M. B. Dickman; E-mail: mdickman@unlnotes.unl.edu; Telephone: 402-472-2849; Fax: 402-472-2853. data analysis rather than acquisition is becoming a limiting factor to progress. As a result, the fungal genetics community has begun emphasizing the importance of interdisciplinary teams as the most effective means of accomplishing genomics era research in agriculture.

This background served as the basis for convening a United States-Israel Binational Agricultural Research and Development Fund (BARD)-sponsored workshop entitled "Molecular Perspectives on Fungal Biology and Pathology: Current Status/Future Research Directions" which took place in Lake Tahoe, NV in October 2002. A group of approximately 40 scientists studying fungal cell biology, molecular genetics, population biology, ecology, fungus-plant interactions, and the emerging field of fungal genomics participated and discussed these issues in the context of agricultural systems. Furthermore, the deans of two agricultural colleges (Neal van Alfen and Yitzhak Hadar, representing two major institutions in the United States and Israel, who are both plant pathologists) offered their perceptions of policy-related issues.

\section{Progress in cell biology and genomics.}

Perspectives, challenges, and "model systems." As illustrated in the most recent volume of The Mycota, considerable progress has been made in the analysis of cell biology in filamentous fungi (Howard and Gow 2001). For example, filamentous fungi undergo dramatic morphological transitions in response to abiotic and biotic signals. In many instances, these transitions are accompanied by alterations in establishment and maintenance of cell polarity. One of the most dramatic of these changes, which occurs in plant pathogens, involves appressorium formation, a process which, over the past years, has been dissected in depth. The ability of Magnaporthe grisea to generate turgor pressure sufficient to breach the synthetic polymer Kevlar as well as plant cuticles is another example of a unique aspect of fungal biology (Howard et al. 1991). This topic also illustrates how new technologies, such as surface plasmon resonance, can be brought to bear to examine these nanoscale mechanical issues in fungal cell biology (Money 1999). It is now known that the turgor pressure in $M$. grisea appressoria is generated by rapid increases in glycerol levels (deJong et al. 1997), which is maintained by the presence of appressorial melanin. It has been known for decades that melanin is required for cuticular penetration in a number of fungal pathogens; melanin-deficient mutants are nonpathogenic. Through the efforts of several laboratories, we now know why this is the case, at least with M. grisea (Dean 1997; Tucker and Talbot 
2001). Not surprisingly, proper regulation of signaling pathways (e.g., cAMP, MAPK) that are responsive to host surface cues is necessary for appressorial development.

Although the genomes of several filamentous fungi have been or are currently being sequenced, the sheer evolutionary breadth of the fungal kingdom, illustrated by the tremendous diversity in ecological niches and lifestyles, precludes the consideration of any single fungal species as representative of the entire kingdom (Perkins 1991). Thus, a significant number of genomes must be sequenced in order to provide adequate representation of the fungi (Bennet 1997). The fungi being selected for sequencing have been chosen because of their tractability, socioeconomic importance, or both. These considerations also have driven the choices of experimental systems investigated by fungal biologists. There is a major ongoing effort to develop technology to improve the tractability of fungal research systems. Saccharomyces cerevisiae and Schizosaccharomyces pombe have been considered the prime models, yielding invaluable information relevant to a wide range of organisms (including other fungi). Scientists whose research was not driven by problems relevant to plant pathology embraced Neurospora crassa and Aspergillus nidulans as models for filamentous fungi, in order to expand the types of questions that could be studied. These systems all have benefited the fungal plant pathology community greatly by paving the way to our fundamental understanding of processes like primary and secondary metabolism, structural and regulatory aspects of fungal growth, and development and signal transduction. Thus, many parameters of fungal life and fitness can be studied with model systems. Nonetheless, the fact that these organisms do not exhibit plant-pathogenic properties as part of their typical lifestyle limits their utility when addressing questions involving actual fungus-plant interactions. More recently, pathogenic species such as Ustilago maydis and M. grisea have gained recognition as model systems for plant pathology. The choice of $M$. grisea may well be attributed (at least in part) to the fact that it is currently the most devastating fungal plant pathogen worldwide (Baker et al. 1997). Furthermore, it is apparent (and expected) that research on this organism focuses primarily on attributes related to pathogenicity, because this is of both fundamental and applied significance. In general, it is becoming more widely accepted that questions concerning pathogenicity should be addressed, whenever possible, by studying specific pathogens, rather than relying on nonpathogenic fungi, even if they are phylogenetically related. Recently, funding for a Fusarium graminearum genomics effort was approved in the United States (and reported on at the BARD meeting), because this pathogen poses a significant and immediate threat to wheat and barley production in North America. As this report was being compiled, the genome sequence was completed and made available online (Table 1).

Comparison of pathogen and model (nonpathogen) genomes promises to identify novel genes in the pathogen with the hypothesis that it is the novel genes that are responsible for the pathogenic lifestyle. However, it is clear that looking only for the differences between pathogen and nonpathogen is an oversimplification. One difficulty is that certain genes involved in pathogenesis are conserved in nonpathogens. Thus, it is evident that drawing functional conclusions using one species as a model for another has limitations because, although orthologous genes exist, orthologous pathways may not.

Saccharomyces cerevisiae has five mitogen-activated protein kinase (MAPK) modules, whereas the filamentous ascomycetes mentioned above have only three. Although not unique to pathogenic fungi, MAPKs clearly have significant roles in plant-fungus interactions. Though $S$. cerevisiae has been instrumental in furthering our understanding of MAPK (and many other genes and proteins), caution must be exercised when ascribing functions from correlations with yeast. For example, the MAPK pmkl of $M$. grisea is similar in sequence to yeast FUS3/KSS1 (involved in mating and cell morphology) and is able to genetically complement a $F U S 3 / K S S 1$ yeast deletion mutant defective in mating. Accordingly, it might be reasonably assumed that pmkl had a similar function in the rice blast fungus. However, when studied in M. grisea, pmkl was shown to be involved not only in mating (as a female), but also in appressorium formation and the actual pathogenic process (Xu and Hamer 1996). In yeast, RAS functions through the cAMP pathway; whereas, in the mammals and the filamentous fungi studied to date (e.g., Colletotrichum spp.), RAS functions through MAP kinase pathways, although these lines may not be entirely distinct, as is typical of signal-transduction pathways. In support of this, evidence for linkage between MAPK and cAMP pathways recently has been shown in $U$.

Table 1. Public domain genomic fungal sequencing efforts (partial list)

\begin{tabular}{|c|c|}
\hline Organism & Website \\
\hline Saccharomyces cerevisiae & unicated to the public \\
\hline Aspergillus fumigatus & $\begin{array}{l}\text { www.ncbi.nlm.nih.gov/cgi-bin/Entrez/map00?taxid=5085 } \\
\text { www.tigr.org/tdb/fungal/ }\end{array}$ \\
\hline A. nidulans & www-genome.wi.mit.edu/annotation/fungi/aspergillus/ \\
\hline Candida albicans & $\begin{array}{l}\text { www.ncbi.nlm.nih.gov/cgi-bin/Entrez/map00?taxid=5476 } \\
\text { www-sequence.stanford.edu/group/candida/ }\end{array}$ \\
\hline Coccidiodes posadasii & www.tigr.org/tdb/fungal/ \\
\hline Cryptococcus neoformans ${ }^{\mathrm{a}}$ & www-genome.wi.mit.edu/annotation/fungi/cryptococcus_neoformans/ \\
\hline Fusarium graminearum ${ }^{\mathrm{b}}$ & www-genome.wi.mit.edu/annotation/fungi/fusarium/ \\
\hline Neurospora crassa & www-genome.wi.mit.edu/annotation/fungi/neurospora/ \\
\hline Magnaporthe grisea & $\begin{array}{l}\text { www-genome.wi.mit.edu/annotation/fungi/magnaporthe/ } \\
\text { www.genome.arizon.edu/mgos/microarray }\end{array}$ \\
\hline Phanerochaete chrysosporium & $\begin{array}{l}\text { www.ncbi.nlm.nih.gov/cgi-bin/Entrez/map00?taxid=5306 } \\
\text { www.jgi.doe.gov/programs/whiterot.htm }\end{array}$ \\
\hline Schizosaccharomyces pombe & www.sanger.ac.uk/Projects/S_pombe/ \\
\hline Phytopathogenic fungi and oomycete EST database ${ }^{c}$ & cogeme.ex.ac.uk/ \\
\hline
\end{tabular}

a Serotype A. Other serotypes also are being sequenced.

b Other fungal genomes that have been prioritized for being sequenced at the Whitehead Institute Center for Genome Research (and are not listed in this table) are: Coccidioides immitis, A. flavus, A. terreus, N. discreta, Rhizopus oryzae, Coprinus cinereus, Batrachochytrium dendrobatidis, Ustilago maydis, Trichophyton rubrum, Paxillus involutus, and Pneumocystis carinii (human and murine).

${ }^{\mathrm{c}}$ Includes expressed sequence tags (EST) from: Mycosphaerella graminicola, Magnaporthe grisea, Blumeria graminis, Botryotinia fuckeliana (anamorph Botrytis cinerea), Colletotrichum trifolii, Verticillium dahliae, Gibberella zeae (anamorph F. graminearum), F. sporotrichioides, Phytophthora infestans, and $P$. sojae. 
maydis (Lee and Kronstad 2002). S. cerevisiae STE12 orthologs in $N$. crassa and A. nidulans are required for mating; however, in $M$. grisea, this appears not to be the case (Park et al. 2002). These few examples emphasize that conserved biochemical functions do not necessarily confer equivalent phenotypes.

Thus, even though model yeasts and filamentous fungi have contributed immensely, and will continue to do so, to understanding fungal biology, precise answers to specific questions in plant pathology must rely on analysis of the actual biological system at hand. Model systems are likely to be of most use when studying conserved aspects of fungal or eukaryotic biology, such as cell cycle regulation, but will be less informative to the more specialized aspects of pathogens, such as host specificity, pathogenicity, and infection-related morphogenesis.

Technology and future research. The rapid completion of the $F$. graminearum genome sequence points to the fact that a typical filamentous fungal genome can be sequenced in approximately a month at a high-throughput genome facility. This rate of progress was unimaginable just a few years ago (Bennett 1997). In addition to genome sequencing, development of the associated fungal-specific bioinformatics infrastructure is needed to accelerate annotation and functional analysis. The acquisition of fungal genome sequences has led the fungal research community to discuss a number of difficult questions concerning how these data will be curated, who will curate them, and how curation will be funded. A constant question is whether there are models that already exist to effectively organize the available and incoming data. However, this could result in a "wait-and-see" attitude, which is inadequate for the current needs. After all, if the fungal genetics community is not seen to make rapid and effective use of genomic data, there would be little to argue for additional fungal genome sequencing projects.

One of the key tools emerging from the advances in genome analyses involves the use of microarrays, which are on the way to becoming part of standard laboratory practice (de Backer et al. 2001; Murad et al. 2001). Whole-genome microarrays for filamentous fungi are now becoming available (e.g., M. grisea and the dimorphic Candida albicans) (Lan et al. 2002). cDNA clones or synthetic oligonucleotides currently are being used to produce partial genome microarrays in several fungal systems. These arrays can be produced relatively inexpensively, but the overall cost of microarray experiments is still significant. Current usage is directed toward gene discovery in both pathogenicity and basic fungal biology-related processes (Kahmann and Basse 2001; Lewis et al. 2002; Lorenz 2002). These data will be used by other researchers in addressing additional questions beyond the specific purpose for which they were generated. Of course, this requires that the data be standardized and maintained in a publicly accessible form (Brazma et al. 2001). Comparison of genome sequences and expression profiles is certain to reveal many features that are conserved or differ between fungal species. However, obtaining full-genome sequence data is a prerequisite for progress in this direction (Pennisi 2001). Several such genomics-based initiatives have reached advanced stages of progress (Soanes et al. 2002) (Table 1; author-recommended internet resources section). Obtaining structural genetic information is a hurdle that, once overcome, will help us progress in functional research. Whole-genome analyses suggest that 30 to $40 \%$ of the potential open reading frames identified have no matches in the database. Functional analysis of these "unknowns" may prove to yield significant findings; perhaps more so than focusing on highly conserved genes that have been intensively characterized in other organisms. In the near future, synteny-based analysis may prove useful in decision-making concerning which unknowns to study first.
We use terms such as saprophyte and pathogen to distinguish lifestyles, but this is a somewhat arbitrary phenotypic distinction and the genetic basis of these differences is not understood. Genome sequence comparisons will provide the candidate genes and hypotheses for functional analyses of lifestyle differences. For example, the Neurospora and Magnaporthe sequences are available for comparison, and differences in gene content will be a focus of investigation. These fungi are considered close relatives, but are estimated to have evolved from a common ancestor 50 to 150 million years ago. Given this evolutionary distance, it is not surprising that they appear to share only about $60 \%$ of their genes. It is important to expand phylogenetic analyses of these and related fungi to consider the question of whether their common ancestor was a plant pathogen, a saprophyte, or a nonpathogenic symbiont. The presence of apparent homologs of genes for secondary metabolism and plant-pathogen virulence factors in Neurospora spp. suggests that the lineage leading to genus Neurospora is just as likely to have lost its ancestral ability to parasitize plants as the lineage leading to genus Magnaporthe is to have gained parasitism (Galagan et al. 2003). Although there is no doubt that comparisons are valuable for the characterization of fungal species, it is important to bear in mind that our understanding of the evolutionary relationships between fungi is incomplete. The availability of genome sequences for representatives across the fungal kingdom is important to anchor these phylogenetic analyses. With a good understanding of the evolutionary relationships between fungi, we will have a more robust context to assess the genetic basis of lifestyle transitions (e.g., mutualists, commensals, biotrophs, or necrotrophs). Thus, the power of genome sequences is equally relevant for cell biology, phylogenetic, and ecological studies and integrates these disciplines with a common data set. Both fungal and plant biologists are interested in the events at the fungushost interface, where communication between the plant and its partner takes place, followed by the changes conferred to the organisms as a result of this process. Although the impressive progress in host-fungus interactions is undeniable (deJong et al. 2002; Jones 2001; Kang et al. 2001; Tyler 2002), our understanding of the essential features responsible for the outcome of a given interaction are still fairly rudimentary. For example, in gene-for -gene interactions, it is now evident that the avirulence and resistance $(a v r / R)$ gene combination alone is not sufficient to induce a specific plant response; another protein or proteins are necessary, at least in the systems that have been studied, and gene-for-gene interactions are clearly complex. With hydrolytic enzymes; a number of the genes encoding such enzymes have been inactivated and, generally, only minor differences with respect to virulence have been observed in such transformants (Apel-Birkhold and Walton 1996; Scott-Craig et al. 1990). Moreover, the fact that Neurospora spp. possess a number of the same activities, but are not pathogens, suggests that other factors are critical for discriminating pathogens and saprophytes. In fact, recent work from a number of groups indicates that disease symptoms may not be entirely due to pathogen factors but originate from co-opted or redirected plant signaling pathways (Dickman et al. 2001; O'Donnell et al. 2001; Pilloff et al. 2002). Microbial toxins generally have been considered essential pathogenicity or virulence determinants and, in many cases, have been thought to elaborate disease symptoms via direct cellular toxicity. It appears, however, that at least some toxins (e.g., victorin, HC-toxin, and oxalic acid) mediate compatibility by perturbing host plant signaling pathways, which leads to disease and disease symptoms. This is an example where molecular and genetic dissection of a component of plant-pathogen interactions has contributed to a change in the way we mechanistically view disease. 
It is evident that signal exchange in the initial stages of "recognition" between plant and fungus is crucial in dictating the outcome of a particular host-microbe interaction. Much of the upstream signal circuitries generally are set and modulated at the protein level and, thus, are poised to respond rapidly to a given stimulus, with the pathway being triggered by physical proximity or protein modification. Therefore, it is likely that future research will be dependent on the development of proteomic tools to elucidate the changes occurring in these networks. These approaches promise to identify unique targets for intervention in plant-pathogen interactions; however, we caution against promising that such targets will be "key" to novel plant protection strategies. Although the search for "silver bullets" that may provide solutions based on interference with plant-host interactions has been intensive, to date, it has not yielded effective solutions. Studies of single $R$ genes, multiple $R$ genes, engineered $R$ genes, systemic acquired resistance, nonhost resistance, pathogenesis-related, and other proteins and specific fungicides all have expanded our knowledge concerning both plant and pathogen biology. However, the information obtained has not been sufficient to be practically implemented to the point of establishing sustainable resistance to the pathogen (Ballvora et al. 2002; Sanchez et al. 2000). Furthermore, it is apparent that the field challenges involved with products that are obtained by molecular breeding are similar to those we face with conventional breeding. Perhaps one of the practical answers that involves taking advantage of $R$ gene polymorphism will be the deployment of $R$ gene complexes as a molecular pyramiding approach, in a manner similar to the 1970s concept of varietal mixtures. With the use of current technology, however, the heterogeneous nature of classical varietal mixtures can be reduced, allowing the reassessment of such an approach (Jones 2001; Wolf and McDermott 1994).

Whole-genome analysis of secreted proteins is a general strategy to identify, in an unbiased manner, potentially interacting proteins (Takken et al. 2000), and studies are already underway in the genera Phytophthora (van West et al. 2001), Aspergillus (Melin et al. 2002), and Magnaporthe to explore this strategy. These studies necessitate the ability to accurately predict secreted proteins encoded in the genome. Gene prediction is a developing area in bioinformatics and improved geneprediction methods specific for fungal genomes are essential. Similar studies with genes for secondary metabolite production, cell-wall-degrading enzymes, and so on will allow us, for the first time, to systematically address gene classes involved in fungus-plant associations. Clearly, these approaches promise to add considerably to our understanding of fungal biology; however, as with any approach, they probably will not suffice to provide complete answers. Thus, the establishment of strong, interlinked study groups in specific areas is one way of promoting effective progress (e.g., active lipidomic, degradomics [Lopez-Otin and Overall 2002], and carbohydrate research centers have demonstrated a realization of the significance of lipids and carbohydrates in cellular communication, and hopefully will integrate with the bioinformatics efforts described above).

Inherent in these analyses is the ability to generate mutants to functionally test the roles of these gene classes. In general, high-throughput production of gene replacement mutants is problematic because of higher rates of nonhomologous recombination in filamentous fungi relative to yeast. Although current technology does permit a brute force approach, technologies to facilitate gene disruption are still needed. In the case of essential genes, gene expression can be controlled with appropriate promoters, conditional alleles, or dominant negative or activated alleles, but high-throughput approaches using these techniques are lacking. However, in many cases, essential genes are conserved across fungal species; therefore, tools developed in one system should greatly aid in these efforts. Gene families, such as MAP kinases, which in some cases are functionally redundant (e.g., FUS3/KSS1), can make functional studies difficult. The standard approach would be to disrupt each gene individually and in combination, requiring a selectable marker for each of the gene family members. Newer approaches being explored include gene silencing RNAi, in which closely related family members could be simultaneously inactivated.

\section{Population genetics and evolutionary biology of fungi.}

Advances in sequence availability and computational methods of phylogenetic analysis have radically changed the potential for studying the evolution of all organisms, including fungi. Genome sequencing has aided in the search for the polymorphic markers used in evolutionary studies. Use of these markers has made it possible to address questions about population structure and cryptic speciation with finer resolution than ever before. Recent analytical techniques, such as haplotype networks and nested clade analysis, when applied to sequence data, are powerful tools for testing associations between genotypes and phenotypes or geographic locations, and for distinguishing between historical events and ongoing processes such as gene flow (Carbone and Kohn 2001). Applying these analytical tools to fungi will require some new ways of thinking, and a careful matching of the questions to the appropriate methods.

Types of questions addressed in population genetics of fungi-particularly plant-pathogenic fungi-may include the following. i) What is the spatial scale of a pathogen population? What "population" needs to be managed? ii) Is a particular outbreak of disease caused by a single successful pathogen clone? How does this clone arise? iii) Are new races or more aggressive strains emerging? How do they arise (recombination, mutation, or migration)? iv) How persistent will novel genotypes be? v) Are pathogens specialized on different hosts? Are subpopulations on different hosts reproductively isolated? vi) Are particular symptoms associated with different pathogen genotypes? (vii) From where is a pathogen introduced?

These questions are at the interface between basic evolutionary questions and an applied perspective, with an aim toward intervention and prevention of pathogen evolution and dispersal. Evolutionary studies may have some predictive value for forecasting the development of pathogen outbreaks or identifying sources of introduced pathogens. This field, sometimes referred to as "molecular epidemiology", is firmly based on evolutionary as well as epidemiological concepts.

Time for a new mindset about evolution and population genetics. The analytical methods used by evolutionary biologists are relatively foreign concepts to many mycologists and plant pathologists. Yet, together with the resources and data available from genomics projects, much more powerful inferences can be made about the evolution and genetics of fungi than have heretofore been made with traditional methods. For example, the ease and reduced costs of sequence generation is leading to increased application of the phylogenetic species concept in fungi and to an appreciation that even morphologically identical fungi have fixed genetic differences (even to the point of defining new species) (Couch and Kohn 2002). Such studies can resolve species-host specificity relationships and point to systems that are likely to be in flux. Methods to compare gene content or measure synteny between fungal genomes also might be developed to resolve the relationships between fungal groups. Although plant pathologists traditionally have been trained with a solid foundation in epidemiological concepts and statistical methods, more training in evolutionary and computational biology will be needed to take full advantage of genome information. These advances in the understanding of 
population structures are immediately applicable to studying ecological relationships at the molecular level. The role of "pathogenicity factors" in determining population structure and their impact on fitness is an important area of research, with implications for resistance-gene deployment strategies. The identification of "pathogenicity factor" genes will provide the basis for examining these genes within populations and between species. These, in turn, will support studies on the roles of these genes in speciation and provide a more accurate view of fungal biodiversity. Some of the questions raised above, along with the relevance of studying fungal fitness to the evolution of sex, natural selection, and fungal diseases, have been discussed recently by Pringle and Taylor (2002).

A clear understanding of fungal biodiversity is important in determining, for example, how to search for novel fungusderived natural products, or in using fungal biodiversity as a measure of the health of the environment (Coppins and Wolseley 2002). The estimation of fungal species numbers and related host specificity is based on the calculation of fungus-to-plant ratios or number of unique fungal species per botanical species. Currently, only about 75,000 fungal species have been carefully described. This number, combined with the rate of discovery of new species and the observation that, as has been demonstrated with bacterial species, up to $70 \%$ or more of fungal species appear to be unculturable, has led to estimates of total fungal species ranging from 500,000 to 10 million. The most generally accepted estimate is currently 1.5 million species (Hawksworth 2001).

\section{Plant pathology and fungal biology do not function in a void.}

Plant pathologists and scientists often focus primarily on the research questions in their own programs. However, our scientific progress cannot be disassociated from other issues involved in our discipline and in the community in which we operate. Thus, it is our responsibility to be aware of and attentive to policy makers, locally, nationally, and internationally, as well as to the general public, who are becoming increasingly aware of environmental, health, and funding issues. Some of these issues include the following. i) Can or should lines be drawn between basic and applied fungal research? ii) Are there ways to evaluate the difference? iii) What distinguishes a plant pathology department from a plant science department? iv) Are we properly educating the next generation of plant pathologists?

The current progress in technology and the subsequent bridging between the different systems studied, along with the functional links established between fundamental processes in cell biology and those of applied interest, have blurred the distinction between basic and applied research. Thus, the differences between question-driven versus problem-driven science (which is one way of trying to distinguish between basic and applied research approaches) are, in many instances, vague. This is true even though a continuous trend in stratification and a concomitant reduction in interactions between scientists involved in different facets of plant pathology (e.g., research departments, extension agents, teaching, and outreach) may be evolving.

The changes in the manner in which plant pathologists publish their research may be an indication of this trend in stratification. Although there is apparent stability in the number of yearly publications in journals in which the emphasis is more problem oriented (e.g., Plant Disease and Plant Pathology), there is an increase in publication number (and also in impact factor) in journals emphasizing molecular approaches to studying plant pathology-related topics (e.g., Molecular PlantMicrobe Interactions and Physiological and Molecular Plant
Pathology). Interestingly, Phytopathology, which appeals potentially to both forums has, in recent years, seen a decline in the number of publications (and impact factor) and may be "suffering" from the fact that it interfaces with two diversifying audiences. Regardless of the trends and changes in research foci, it is critical to encourage high-quality research that addresses short-, medium-, and long-term needs of agriculture. The presence of multiple life sciences colleges within institutes of higher education creates an apparent redundancy in life science-related programs. The occupational trends in the developed world have resulted in the continuous reduction of workers directly involved in agriculture. Figures for 1998 are: $2.4 \%$ of workers are directly involved in agriculture in Israel $(6.3 \%$ in 1980), $2.7 \%$ in the United States (3.6\% in 1980), about $3.2 \%$ in western Europe (about $5.5 \%$ in 1980), about $25 \%$ in eastern Europe (about $27 \%$ in 1980), and $47.5 \%$ in China $(68.7 \%$ in 1980 ), based on World Bank and Israel Central Bureau of Statistics datasets. However, because the rate of food production will have to be maintained (and perhaps, in time, increased), the link between plant pathologists and agricultural production remains. In his review, Luis Sequeira has stated that: "Plant pathology exists as an independent field because the growers need us. The day that connection is broken, plant pathology will lose its independence and may continue to exist only as a branch of plant science departments" (Sequeira 2000).

Plant pathology (and, for that matter, agricultural sciences in general) combines new tools and approaches that are common to all areas of biology. Thus, environmental sciences and studies of natural resources, biotechnology, genomics, and bioinformatics, as well as nutritional aspects of food production and quality, are part and parcel of a modern plant pathologist's education and research program. On the basis of the assumption that plant pathology should continue to progress as a distinct discipline but one that has traditionally incorporated numerous other areas of biological sciences (as mentioned above), we should learn to emphasize the fact that the multidisciplinary nature of plant pathology is one of the attributes that makes this discipline so exciting. As such, it also has attracted scientists from numerous other disciplines who have made seminal contributions to the field. In light of Sequeira's statement, this multidisciplinary facet of molecular plant pathology also must include establishing an understanding of, and hands-on contact with, applied problems in the field. Plant pathologists may work primarily in areas nearly indistinguishable from the scientist in the biology department and must compete directly for research funds. However, the plant pathologist also must understand the problems faced by agricultural producers and, over time, develop a program that is both competitive at the highest level for funding and develop research that has the potential to directly impact crops in the field. Other plant pathologists work primarily with growers or with crops in the field, conducting research to maximize plant productivity. These scientists must follow the most recent laboratory research and assimilate the impact of genomics in a way that will most effectively carry out their efforts in the field. The job of the modern plant pathologist requires the need to try and excel in a set of diverse subdiciplines. This creates a significant challenge in an era when highly specialized research is conducted in other fields of biology. The current trend is to hire scientists that look very much like the typical biologist into the plant pathology faculty position (after all, obtaining funding and publishing in high-impact journals is the primary factor in hiring in any life science field). However, these new faculty also have the understanding that involvement in research relative to plant productivity is essential to their success. Balancing these demands and preparing students who will be ready to face these demands is the single biggest challenge 
facing the discipline of plant pathology. Therefore, despite the symptoms of stratification discussed above, survival of the discipline depends more than ever on cooperation between "basic" and "applied" scientists.

\section{Plant pathology - a discipline in uncertainty - the economic link.}

Along with the celebration of scientific advance, questions concerning the future needs and fate of plant pathology were discussed at the BARD meeting. It is clear that not all of the significant issues at hand could be thoroughly dealt with at one workshop. Nonetheless, the authors of this report find it appropriate to draw attention to additional issues that warrant attention. The technological advances that have bridged the distance between basic and applied science also have strengthened the link between profit-gaining enterprises and academic or government nonprofit organizations. For the most part, industry has invested in these ties with the primary intention of short- or long-term profit. Researchers have benefited from these interactions in the form of funding as well as intellectual gains. The interaction between the agricultural industry and academia has advanced to the point where many academic researchers look upon industry as a source for a significant portion of their research funding. The gains can be enormous, yet there also are several potential pitfalls. Has industry been purchasing intellect and lab space at highly profitable prices (perhaps "subsidized", in part, by the public)? Not withstanding, the flow of information between academia and industry is far from even. Thus, the current paradigm appears to be that data concerning fungal biology that is gained in industry is not released to the public, even if it is not used. Interestingly, at times, it appears that, once public funding is made available some, companies are more cooperative in sharing information (e.g., Monsanto and Bayer with regard to $A$. nidulans and $U$. maydis genome sequences, respectively; Table 1). What will be the effect of declining research, development, and sales of agricultural chemicals on plant pathology research that has become more and more dependent on industrial funding? Have the research links and association of academic researchers with industrial partners hampered the standing of the former in the eyes of the public (including public funding policy makers)? Have plant pathologists become more dependent on industrial priorities when planning their research? Reduction in government funding levels certainly has contributed further to such trends. Analyzing the situation becomes more complex when the national and global changes in agriculture, influenced by economics, politics, and even emotions, are integrated into the picture. Public awareness and involvement in agriculture and environmental-related issues such as food safety, adverse affects of agro-chemicals, and the various concerns with genetically modified organisms (GMOs), warrant the availability of impartial experts, including molecular plant pathologists, to make scientific progress on the one hand, yet provide the general public (including the scientific community) assurance as to the altruistic motivating force involved in the introduction of new technologies on the other. In general, we (scientists and industry) have not communicated to the public sector exactly what it is we do with respect to "molecular breeding" in a meaningful manner. As a result, this has become a contentious issue. Public opinion has, to an alarming degree, become emotionally based. Regardless of opinion, we should strive for informed views. This is crucial for many reasons, and it should be emphasized that GMO-based food probably is inevitable. For example, $80 \%$ of the U.S. soybean crop for this year will use bioengineered seed. It also is necessary to emphasize that the current alternative of chemicals, besides being costly, has a negative impact on the environment. We also must realize that it is more popular to describe negative aspects of agricultural biotechnology (e.g., the case of the monarch butterfly) (Gatehouse et al. 2002) than the positive intentions and results from agricultural biotechnology efforts, thus making the beneficial aspects of this science more difficult to disseminate. As mentioned, plant pathologists, like other scientists, do not function in a void; thus, plant pathologists should be attentive to the changes and transitions in modern agriculture in the broadest sense possible. Members of the plant pathology community also must assume responsibility for the future of the discipline and initiate the proper actions to benefit the community. If plant pathologists maintain their mission to insure plant health and food quality while not compromising their scientific merit on the one hand and academic freedom on the other, the chances of achieving their fundamental goals and, at the same time, preserving the discipline can occur. This era of uncertainty in plant pathology, (and agriculture in general) is heightened due to lack of increased government funding; diminishing industry support due to mergers, consolidation, and the stock market; GMO issues, especially in Europe (even though there are increasing indications of a reassessment of the rigid approaches); and over production, coupled with world trade issues (e.g., tariff barriers).

Is the discipline of plant pathology relevant to a wealthy society and worthy of support? The answer is clearly yes. Agricultural producers are strong supporters of the discipline because reducing plant disease would increase profits dramatically. The remaining $97 \%$ of the population, who are consumers rather than producers, may be less concerned about plant disease because, in general, produce at the market is plentiful and food security is taken for granted. However, significant disease problems do arise that attract broad societal interest and gain support for plant pathology research. Therefore, plant pathologists must operate in accordance with both the economics of science and the economics of agriculture. If the "market' (consumer or political) has a need to solve a problem or invest in it, those are both niches in which plant pathologists can operate, and researchers should exhibit flexibility concerning managing newly available resources to address these problems. Of course, a fundamental problem with the discipline is that plant pathologists are, at times, expected to abandon current research efforts to put out "fires". A history of cooperation with this approach (even though based on good will) has created a general attitude toward our field that has resulted in maintenance of expectations on the one hand along with parallel erosion of funding on the other. Maintaining a connection with growers in the face of dwindling funds to support research that addresses their direct concerns has become the paradox that may threaten plant pathology as a discipline. One should anticipate the outcome of the demand to put out fires without sufficient funding to be reduced focus, reduced quality in scientific achievements, or both. Such a situation would impose a significant disadvantage on plant pathologists when competing for rank and funding with fellow biologists. We should assimilate the fact that maintaining high scientific standards and garnering funding in competition with other biologists is the only avenue for longterm success in our field. However, this does not, on its own, provide a solution to the paradox.

It is undeniable that, when considering basic and applied science, molecular plant pathologists often find themselves between a rock and hard place. As such, we should be a broad-based community ready to put out the fires when they occur, but solidly grounded in research to explore hypotheses involving disease processes and mechanisms for plant disease prevention or resistance. Seminal discoveries (with immediate or long-term impact on applied aspects of plant pathology) have resulted from ventures originally intended to obtain "only" fundamental understanding in fungal biology or fungus-host interactions. 
This fact supports the importance and benefits of "allowing" scientists to explore avenues of research that may not appear to have direct and obvious impact on the agricultural community.

If the points mentioned above will be considered by the members of the molecular plant pathology community, as well as by funding agencies (whose reviewers are frequently members of this community), we believe that our discipline will flourish, even in this age of uncertainly in agricultural practice and sciences.

\section{CONCLUSIONS}

As technological advances have facilitated the probing of any fungal system of interest, fundamental fungal biology and fungal plant pathology have become intertwined. This has resulted in changes in how we view fungi in their natural or imposed habitats. The fact is that available tools have significantly improved our capability to experimentally approach questions regarding fungi as plant pathogens and bring together plant pathologists representing subdisciplines of fungal biology (e.g., genetics, cell biology, epidemiology, ecology, and so on), some of which have seemingly diverged over the years, as well as our counterparts in other life science departments. The potential for some of these renewed interactions has been addressed in this review.

Our ability to generate vast quantities of data provides exciting possibilities for dissecting biological processes; yet, at the same time, poses a significant challenge in data analysis and organization. The accumulation of data via genome sequencing, microarrays, and proteomic analyses is likely to occur at an accelerated pace. Thus, we can anticipate that, in contrast to past decades, data analysis, rather than data acquisition, will prove to be the limiting factor in scientific progress. As the number of potential variables concomitantly analyzed increases, so does the necessity to properly pose the addressed biological question or questions. The ability to simplify the question may be instrumental in focusing on the objective and obtaining an answer that will enable the experimenter to reach meaningful conclusions. Thus, even in this era of "holistic" data sets, a reductionist approach is likely to prevail. This, of course, does not diminish the requirement to develop and maintain an understanding of the biological nature of the study system and maintain a "feel for the organism".

It is conceivable that such data sets can provide information useful to many scientists (involved in addressing different questions); therefore, it is our responsibility to organize and maintain such data sets in a multi-user-accessible manner. If this is done, not only will we reduce unnecessary repetition and costs, but we also will help maintain the stepwise and interdependent progression of the scientific course.

Even though plant pathology has traditionally used bioinformatics in the form of statistical analysis in disease assessment and epidemiology and in the development of algorithms for disease forecasting, the opportunities for collaboration with scientists from other fields is expanding rapidly. The continuous development of appropriate software coupled with statistical analysis of data is just one example of such evolving collaborations. The prospects of further involvement of physicists, chemists, and mathematicians are exciting.

Several promising "silver bullets" have been offered as potential solutions for disease control. However, none of those based on host factors has yet had a durable impact. Nonchemical disease control measures are a necessity; therefore, the quest for silver bullets or alternative strategies will continue. Looking at fungal determinants may well prove to be a worthwhile avenue to pursue. In any case, the need to maintain a working contact with agriculture should be at the core of plant pathology. It is through accumulated experience, positive and negative, along with technical innovations (mentioned in this review) that we can continue to face and solve problems of the future.

Plant pathology as a discipline is at a stage of transition. We currently are suffering from a more restrictive research climate due to regulatory constraints, declining research support, and unfavorable changes in hiring practices. However, the prospects of maintaining our independence can be very good, provided we are proactive in our research as well as our interaction with students, institutions, and the general public. The use of developing technologies and databases for analysis of fungal lifestyles, plant-fungal signaling, and disease development at the cellular and population levels, along with issues such as increases in disease agent transfer as a result of international commerce or travel (can events similar to the SARS epidemic occur to our crops?), new problems, and new diseases associated with new crops, imports, and transgenic plants (including increased diagnostic capabilities) are all likely to lead to significant biological findings which, at the same time, will contribute to the well being of our communities.

Regardless of the current status of plant health in the developed world, or of political changes, the need to supply increased quantities of healthy food to a growing global population will not diminish. The responsibilities imposed on plant pathologists worldwide have been, still are, and will continue to be to maintain contact with the agricultural world and properly educate the next generations of specialists in the field.

\section{ACKNOWLEDGMENTS}

This overview is based on workshop No. W-61-02 supported by BARD, the U.S.-Israel Binational Agricultural Research and Development Fund. We acknowledge the active participation and input from the workshop participants: F. Banuett, R. Bostock, G. Carroll, C. Chen, L. Ciuffetti, W. Fry, S. Gold, Y. S. Ha, Y. Hadar, A. Harel, S. Harris, S. Horowits, B. A. Horwitz, T. Katan, N. Keller, C. Kistler, J. Kronstad, A. Lichter, J. Lorang, J. Manners, S. Marek, R. Metzenberg, M. Milgroom, N. Read, R. Redman, J. Rollins, A. Sharon, F. Trail, P. Tudzynski, , B. Valent, N. van Alfen, T. Wolpert, J. R. Xu, E. Yatzkan, and C. Ziv; and we thank I. Chet, Z. Adam, A. Vidaver, and H. Wilkinson for discussions and critical comments.

\section{LITERATURE CITED}

Apel-Birkhold P. C., and Walton, J. D. 1996. Cloning, disruption, and expression of two endo-beta 1,4-xylanase genes, XYL2 and XYL3, from Cochliobolus carbonum. Appl. Environ. Microbiol. 62:4129-4135.

Baker, B., Zambryski, P., Staskawicz, B., and Dinesh-Kumar, S. P. 1997. Signaling in plant-microbe interactions. Science 276:726-733.

Ballvora, A., Ercolano, M. R., Weib, J., Meksem, K., Bormann, C. A., Oberhagemann, P., Salamini, F., and Gebhardt, C. 2002. The $R 1$ gene for potato resistance to late blight (Phytophthora infestans) belongs to the leucine zipper/NBS/LRR class of plant resistance genes. Plant J. 30:361-371.

Bennett, J. W. 1997. White paper: Genomics for filamentous fungi. Fungal Genet. Biol. 21:3-7.

Brazma, A., Hingamp, P., Quackenbush, J., Sherlock, G., Spellamn, P., Stoeckert, C., Aach, J., Ansorge, W., Ball, C. A., Causton, H. C. Gaasterland, T., Glenisson, P., Holstege, F. C. P., Kim, I. F., Markowitz, V., Matese, J. C., Parkinson, H., Robinson, A., Sarkans, U., SchulzeKremer, S., Stewart, J., Taylor, R., Vlo, J., and Vingron, M. 2001. Minimum information about a microarray experiment (MIAME)ward standards for microarray data. Nat. Genet. 29:365-371.

Carbone, I., and Kohn, L. M. 2001. A microbial population-species interface: nested cladistic and coalescent inference with multilocus data. Mol. Ecol. 10:947-964.

Coppins B. J., and Wolseley, P. 2002. Lichens of tropical forests. Pages 113-131 in: Tropical Mycology: Volume 2, Micromycetes. R. Watling, J. C. Frankland, A. M. Ainsworth, S. Isaac, and C. H. Robinson, eds. CABI Publishing, Wallingford, U.K.

Couch, B. C., and Kohn, L. M. 2002. A multilocus gene genealogy concordant with host preference indicates segregation of a new species, 
Magnaporthe oryzae, from M. grisea. Mycologia 94:683-693.

Dean, R. A. 1997. Signal pathways and appressorium morphogenesis Annu. Rev. Phytopathol. 35:211-234.

de Backer, M. D., Ilyina, T., Ma, X. J., Vandoninck, S., Luyten, W. H., and Vanden-Bossche, H. 2001. Genomic profiling of the response of Candida albicans to itraconazole treatment using a DNA microarray. Antimicrob. Agents Chemother. 45:1660-1670.

deJong, C. F., Takken, F. L., Cai, X., de Wit, P. J., and Joosten, M. H 2002. Attenuation of Cf-mediated defense responses at elevated temperatures correlates with a decrease in elicitor-binding sites. Mol. Plant-Microbe Interact. 15:1040-1049.

deJong, J. C., McCormack, B. J., Smirnoff, N., and Talbot, N. J. 1997. Glycerol generates turgor in rice blast. Nature 389:244-245.

Dickman, M. B., Park, Y. K., Oltersdorf, T., Li, W., Clemente, T., and French, R. 2001. Abrogation of disease development in plants expressing animal anti-apoptotic genes. Proc. Natl. Acad. Sci. U.S.A. 98: 6957-6962.

Galagan, J. E., Calvo, S. E., Borkovich, K. A., Selker, E. U., Read, N. D., FitzHugh, W., Ma, L.-J., Smirnov, S., Purcell, S., Rehman, B., Elkins, T., Engels, R., Wang, S., Nielsen, C. B., Butler, J., Jaffe, D., Endrizzi, M., Qui, D., Ianakiev, P. Bell-Pedersen, D. Nelson, M. A., WernerWashburne, M., Selitrennikoff, C. P., Kinsey, J. A., Braun, E. L., Zelter, A., Schulte, U., Kothe, G. O., Jedd, G., Mewes, W., Staben, C., Marcotte, E., Greenberg, D., Roy, A., Foley, K., Naylor, J., StangeThomann, N., Barrett, R., Gnerre, S., Kamal, M., Kamvysselis, M. Bielke, C., Rudd, S., Frishman, D., Krystofova, S., Rasmussen, C. Metzenberg, R. L., Perkins, D. D., Kroken, S., Catcheside, D., Li, W., Pratt, R. J., Osmani, S. A., DeSouza, C. P. C., Glass, L. Orbach, M. J., Berglund, J. A., Voelker, R., Yarden, O., Plamann, M., Seiler, S., Dunlap, J., Radford, A. Aramayo, R., Natvig, D. O., Alex, L. A., Mannhaupt, G., Ebbole, D. J., Freitag, M., Paulsen, I., Sachs, M. S., Lander, E. S., Nusbaum C., and Birren, B. 2003. The genome sequence of the filamentous fungus Neurospora crassa. Nature 422:859868

Gatehouse, A. M. R., Ferry, N., and Raemaekers, J. M. 2002. The case of the monarch butterfly: a verdict returned. Trends Genet. 18:249-251.

Hawksworth, D. L. 2001. The magnitude of fungal diversity: the 1.5 million species estimate revisited. Mycol. Res. 105:1422-1432.

Howard, R. J., Ferrari, M. A., Roach, D. H., and Money, N. P. 1991. Penetration of hard substrates by a fungus employing enormous turgor pressure. Proc. Natl. Acad. Sci. U.S.A. 88:11281-11284

Howard, R. J., and Gow N. A. R., eds. 2001. Biology of the fungal cell. In: The Mycota. K. Esser, ed. Springer-Verlag, Berlin.

Jones, J. D. G. 2001. Putting knowledge of plant disease resistance genes to work. Curr. Opin. Plant Biol. 4:281-287.

Kahmann R., and Basse, C. 2001. Fungal gene expression during pathogenesis-related development and host plant colonization. Curr. Opin. Microbiol. 4:374-380.

Kang, S. Lebrun, M. H., Farrall, L., and Valent, B. 2001. Gain of virulence caused by insertion of a Pot3 transposon in a Magnaporthe grisea avirulence gene. Mol. Plant-Microbe Interact. 14:671-674.

Lan, C. Y., Newport, G. Murillo, L. A., Jones, T., Scherer, S., Davis, R. W., and Agabian, N. 2002. Metabolic specialization associated with phenotypic switching in Candida albicans. Proc. Natl. Acad. Sci. U.S.A. 99:14907-14912.

Lee, N., and Kronstad, J. W. 2002. ras2 Controls morphogenesis, pheromone response, and pathogenicity in the fungal pathogen Ustilago maydis. Euk. Cell 1:954-966.

Lewis, Z. A., Correa, A., Schwerdtfeger, C., Link, K. L., Xie, X., Gomer, H. R., Thomas, T., Ebbole, D. J., and Bell-Pedersen, D. 2002. Overexpression of WHITE COLLAR-1 (WC-1) activates circadian clock-associated genes, but is not sufficient to induce most light-regulated gene expression in Neurospora crassa. Mol. Microbiol. 45:917-931.

Lopez-Otin, C., and Overall, C. M. 2002. Protease degradomics: a new challenge for proteomics. Nat. Rev. Mol. Cell. Biol. 3:509-519.

Lorenz, M. C. 2002. Genomic approaches to fungal pathogenicity. Curr. Opin. Microbiol. 5:372-378.

Melin, P., Schnurer, J., and Wagner, E. G. 2002. Proteome analysis of Aspergillus nidulans reveals proteins associated with the response to the antibiotic concanamycin A, produced by Streptomyces species. Mol. Genet. Genomics. 267:695-702.

Money, N. P. 1999. Biophysics: Fungus punches its way in. Nature 401:332-333.

Murad, A. M., d'Enfert, C., Gaillardin, C., Tournu, H., Tekaia, F., Talibi, D., Marechal, D., Marchais, V., Cottin, J., and Brown, A. J. 2001. Transcript profiling in Candida albicans reveals new cellular functions for the transcriptional repressors CaTup1, CaMig1 and CaNrg1. Mol. Microbiol. 42:981-993.

O’Donnell, P. J., Jones, J. B., Antoine, F. R., Ciardi, J., and Klee, H. J. 2001. Ethylene-dependent salicylic acid regulates an expanded cell death response to a plant pathogen. Plant J. 25:315-323.

Park, G., Xue, G. Y., Zheng, L., Lam, S., and Xu, J. R. 2002. MST12 regulates infectious growth but not appressorium formation in the rice blast fungus Magnaporthe grisea Mol. Plant-Microbe Interact. 15:183192.

Pennisi, E. 2001. The push to pit genomics against fungal pathogens Science 292:2273-2274.

Perkins, D. D. 1991. In praise of diversity. Pages 3-26 in: More Gene Manipulations in Fungi. J. W. Bennet and L. L. Lasure, eds. Academic Press, San Diego, CA.

Pilloff, R. K., Devadas, S. K., Enyedi, A., and Raina, R. 2002. The Arabidopsis gain-of-function mutant $d l l$ spontaneously develops lesions mimicking cell death associated with disease. Plant J. 30:61-70.

Pringle, A., and Taylor, J. W. 2002. The fitness of filamentous fungi. Trends Microbiol. 10:474-481.

Sanchez, G. M., Smart, C. D., Simko, I., Bonierbale, M., Ewing, E. E., May, G., Greenland, A., and Fry, W. E. 2000. Identification of two new R-genes to Phytophthora infestans from Solanum berthaultii. (Abstr.) Phytopathology 90:S68.

Scott-Craig, J. S., Panaccione, D. G., Cervone, F, and Walton, J. D. 1990. Endopolygalacturonase is not required for pathogenicity of Cochliobolus carbonum on maize. Plant Cell 2:1191-1200.

Sequeira, L. 2000. Legacy for the millennium: a century of progress in plant pathology. Annu. Rev. Phytopathol. 38:1-17.

Soanes, D. M., Skinner, W., Keon, J., Hargreaves, J., and Talbot, N. J. 2002. Genomics of phytopathogenic fungi and the development of bioinformatic resources. Mol. Plant-Microbe Interact. 15:421-427.

Takken, F. L. W, Luderer, R., Gabriëls, S. H. E. J., Westerink, N., Lu, R., de Wit, P. J. G. M., and Joosten, M. H. A. J. 2000. A functional cloning strategy, based on a binary PVX-expression vector, to isolate HR-inducing cDNAs of plant pathogens. Plant J. 24:275-283.

Tucker, S. L., and Talbot, N. J. 2001. Surface attachment and pre-penetration stage development by plant pathogenic fungi. Annu. Rev. Phytopathol. 39:385-417

Tyler, B. M. 2002. Molecular basis of recognition between Phytophthora pathogens and their hosts. Annu. Rev. Phytopathol. 40:137-167.

van West, P., Lis, S., Shepherd, S. J., and Gow, N. A. R. 2001. Identification of stage specific secreted proteins in Phytophthora sp. 10th Int Congr. Mol. Plant Microbe Interact. Madison, WI.

Wolf, M. S., and McDermott, J. M. 1994. Population genetics of plant pathogen interactions: the example of the Erysiphe graminis-Horedum vulagare pathosystem. Annu. Rev. Phytopathol. 32:89-113.

Xu, J. R., and Hamer, J. G. 1996. MAP kinase and cAMP signaling regulate infection structure formation and pathogenic growth in the rice blast fungus Magnaporthe grisea. Genes Dev. 10:2696-2706.

\section{AUTHOR-RECOMMENDED INTERNET RESOURCES}

Generic Model Organism Database: www.genome.arizona.edu/mgos

Microarray Gene Expression Data Society: www.mged.org

The Consortium for the Functional Genomics of Microbial Eukaryotes: www.cogeme.man.ac.uk/

The Fungal Genome Initiative: www-genome.wi.mit.edu/seq/fgi/

The Institute for Genomic Research database: www.tigr.org/tdb/mdb/ mdbinprogress.html

The National Center for Food and Agricultural Policy; Biotechnology Assessment Program: www.ncfap.org/biotech.htm 